\title{
ChemComm
}

CrossMark \& click for updates

Cite this: Chem. Commun., 2015, 51,15141

Received 8th July 2015,

Accepted 20th August 2015

DOI: $10.1039 / \mathrm{c5cc05647k}$

www.rsc.org/chemcomm

\section{Homochiral metal phosphonate nanotubes $\dagger$}

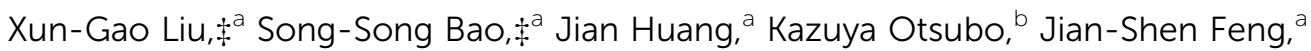 \\ Min Ren, ${ }^{a}$ Feng-Chun Hu, ${ }^{c}$ Zhihu Sun, ${ }^{c}$ Li-Min Zheng, ${ }^{* a}$ Shiqiang Wei ${ }^{* c}$ and \\ Hiroshi Kitagawa*b
}

\begin{abstract}
A new type of homochiral metal-organic nanotubular structures based on metal phosphonates are reported, namely, $(R)$ - or (S)-[M(pemp)$\left.\left(\mathrm{H}_{2} \mathrm{O}\right)_{2}\right]\left[\mathrm{M}=\mathrm{Co}^{\prime \prime}(1), \mathrm{Ni}^{\prime \prime}(2)\right]$ [pemp ${ }^{2-}=(R)$ - or $(S)$-(1-phenylethylamino)methylphosphonate]. In these compounds, the tube-walls are purely inorganic, composed of metal ions and O-P-O bridges. The cavity of the nanotube is hydrophilic with one coordination water pointing towards the center, while the outer periphery of the nanotube is hydrophobic, decorated by the phenylethyl groups of pemp ${ }^{2-}$. The thermal stabilities, adsorption and proton conductivity properties are investigated.
\end{abstract}

Since the discovery of carbon nanotubes by Iijima in $1991,{ }^{1}$ nanotubular materials have received considerable attention due to their unique physical and chemical properties and potential applications including catalysis, drug delivery, energy storage and sensors. ${ }^{2}$ The fabrication of nanotubular materials is also very important for understanding ion or water transport within complex biological channels. ${ }^{3}$ So far a number of pure inorganic or organic nanotubular materials have been constructed successfully through rolling-up or supramolecular approaches. ${ }^{4,5}$ In contrast, there are much fewer metal-organic hybrid systems showing discrete or one-dimensional (1D) tubular structures. ${ }^{6-10}$ Most of the work focused on the structures, while their functions remain largely unexplored. ${ }^{9}$

On the other hand, homochiral structures are ubiquitous in nature. The combination of chirality with porosity can result in materials that have potential applications in enantioselective separation and catalysis, nonlinear optics and multifunctional materials. ${ }^{11}$

\footnotetext{
${ }^{a}$ State Key Laboratory of Coordination Chemistry, School of Chemistry and Chemical Engineering, Collaborative Innovation Center of Advanced Microstructures, Nanjing University, Nanjing 210093, China. E-mail: Imzheng@nju.edu.cn

${ }^{b}$ Division of Chemistry, Graduate School of Science, Kyoto University,

Kitashirakawa-Oiwakecho, Sakyo-ku, Kyoto 606-8502, Japan.

E-mail: kitagawa@kuchem.kyoto-u.ac.jp

${ }^{c}$ National Synchrotron Radiation Laboratory, University of Science and Technology of China, Hefei 230029, P. R. China. E-mail: sqwei@ustc.edu.cn

$\dagger$ Electronic supplementary information (ESI) available: Synthetic details, structural data, SEM, IR, PXRD, TG, additional EXAFS, adsorption/desorption isotherms and proton conductivity figures. CCDC 696828-696830 and 1060995. For ESI and crystallographic data in CIF or other electronic format see DOI: 10.1039/c5cc05647k \$ These authors contributed to this work equally.
}

As far as we are aware, homochiral zeolites still remain a synthetic challenge with only one exception of pure chiral silica. ${ }^{12}$ Homochiral metal-organic frameworks (MOFs) are more common than chiral zeolites, ${ }^{11,13}$ but those with tubular architectures are extremely rare. ${ }^{10}$ Metal phosphonates as an important class of metal-organic hybrid materials can be good candidates for the construction of porous materials with high thermal and water stabilities. ${ }^{14,15}$ Despite the increasing number of metal phosphonates reported in the past two decades, however, only two uranyl compounds exhibit nanotubular structures. ${ }^{16}$ Homochiral metal phosphonates are rare,,${ }^{17,18}$ and those with tubular structures have never been documented.

In this paper, we report the first examples of homochiral metal phosphonate nanotubes, namely, $(R)-\left[\mathrm{Co}(\right.$ pemp $\left.)\left(\mathrm{H}_{2} \mathrm{O}\right)_{2}\right](\boldsymbol{R}-\mathbf{1})$, $(S)-\left[\mathrm{Co}(\right.$ pemp $\left.)\left(\mathrm{H}_{2} \mathrm{O}\right)_{2}\right] \quad(\boldsymbol{S}-\mathbf{1}), \quad(R)-\left[\mathrm{Ni}(\right.$ pemp $\left.)\left(\mathrm{H}_{2} \mathrm{O}\right)_{2}\right] \quad(\boldsymbol{R}-\mathbf{2})$ and $(S)-\left[\mathrm{Ni}(\right.$ pemp $\left.)\left(\mathrm{H}_{2} \mathrm{O}\right)_{2}\right](\mathrm{S}-2)\left[\mathrm{pemp}^{2-}=(R)-\right.$ or $(S)-(1-$ phenylethylamino)methylphosphonate]. They provide a new type of chiral nanotubes among the metal-organic hybrid materials. The compounds can be dehydrated and rehydrated while maintaining their chiral tubular nature, as confirmed by the powder XRD, CD and XAFS measurements. The adsorption and proton conductivity properties of these compounds are also investigated.

Compounds $R-1, S-1, R-2$ and $S-2$ were synthesized through hydrothermal reactions of cobalt or nickel salt and $\mathrm{pempH}_{2}$ at $140{ }^{\circ} \mathrm{C}$ for 4 days. These compounds are isomorphous according to their powder XRD patterns (Fig. S3-S6, ESI $\dagger$ ). The $R$ - and $S$-isomers are a pair of enantiomers. Single-crystal structural determination reveals that all crystallize in the hexagonal chiral space group $\mathrm{PG}_{3}$ (Table S1, ESI $\dagger$ ).\& Take $\boldsymbol{R}-\mathbf{1}$ as an example. The asymmetric unit contains one independent $\mathrm{Co}^{\mathrm{II}}$ ion, one $R$-pemp ${ }^{2-}$ ligand and two coordinated water molecules (Fig. 1a, left). Each $\mathrm{Co}^{\mathrm{II}}$ ion adopts a slightly distorted octahedral coordination geometry, surrounded by three phosphonate oxygen $(\mathrm{O} 1, \mathrm{O} 2 \mathrm{~A}, \mathrm{O} 3 \mathrm{~B})$ atoms and one nitrogen (N1) atom from three equivalent $R$-pemp ${ }^{2-}$ ligands and two water molecules [Co1-O: 2.070(4)-2.180(3) $\AA$, Co1-N: 2.235(5) $\AA$ ]. The enantiopure $R$-pemp ${ }^{2-}$ chelates the Co atom through $\mathrm{N} 1$ and $\mathrm{O} 1$ atoms, and bridges the equivalent Co atoms via the other two phosphonate oxygens $(\mathrm{O} 2, \mathrm{O} 3)$, hence inducing the chirality on the metal centers with $\Lambda$-configuration in $\boldsymbol{R}$-1. Each $\left\{\mathrm{PO}_{3} \mathrm{C}\right\}$ tetrahedron 
(a)

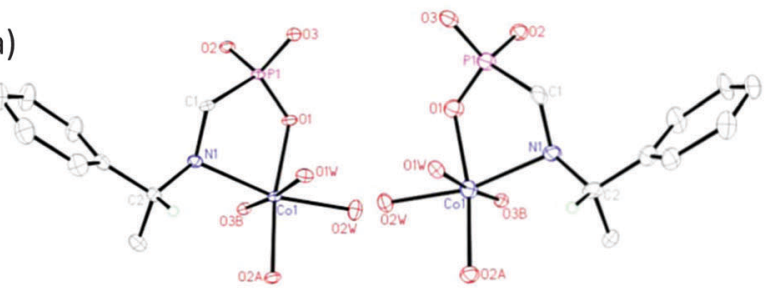

(b)
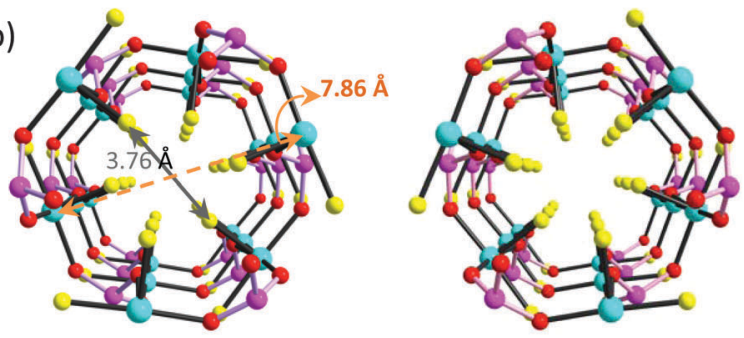

(c)

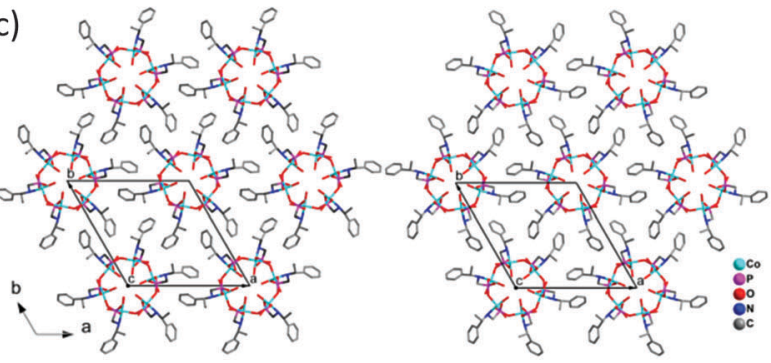

(d)

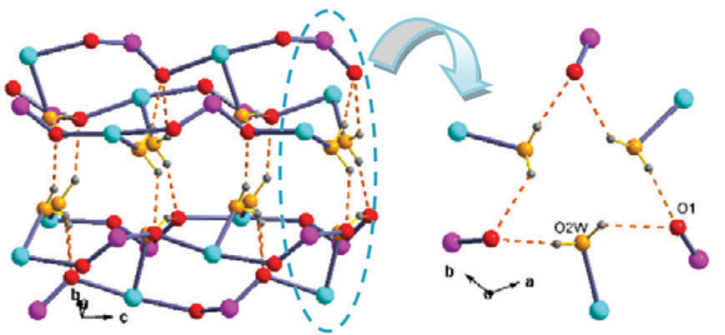

Fig. 1 (a) Building units of structures $\boldsymbol{R}-\mathbf{1}$ (left) and $\boldsymbol{S} \mathbf{- 1}$ (right); (b) the inorganic tubes in structures $\boldsymbol{R}-\mathbf{1}$ (left) and $\boldsymbol{S} \mathbf{- 1}$ (right) viewed along the $c$-axis. The coordination water are highlighted in yellow; (c) structures $\boldsymbol{R}-\mathbf{1}$ (left) and $\mathbf{S}-\mathbf{1}$ (right) packed along the $\boldsymbol{C}$-axis. (d) Hydrogen bond interactions inside the nanotube of $\boldsymbol{R}-\mathbf{1}$.

is corner-sharing with three $\left\{\mathrm{CoO}_{5} \mathrm{~N}\right\}$ octahedra through three phosphonate oxygen atoms and vice versa, forming an infinite chiral nanotube running along the $6_{3}$ screw axis in the $c$-direction (Fig. $1 \mathrm{~b}$, left). The $\mathrm{Co} \cdots$ Co distances over the O-P-O bridges are 4.998(1) $\AA$ and 6.169(1) A. One of the two coordinated water molecules (O2W) point to the center of the window, and form hydrogen bonds with

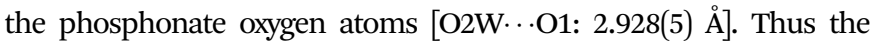
cavity of the nanotube is hydrophilic, while the outer periphery of the nanotube is hydrophobic decorated by the phenylethyl groups of $R$-pemp ${ }^{2-}$. The diameter of the nanotube, defined by the distance between the opposite coordinated water oxygen chains, is $c a .3 .76 \AA$ (3.01 A between opposite water hydrogen chains) (van der Waals radii not taken into account), similar to those in a 3D compound $\mathrm{Zn}\left(\mathrm{O}_{3} \mathrm{PCH}_{2} \mathrm{OH}\right) .{ }^{19}$ The distance of opposite cobalt chains is $c a .7 .86 \AA$ (van der Waals radii not taken into account), which defines approximately the inner diameter after removal of water. The nanotubes are packed in a hexagonal arrangement, where van der Waals interactions are dominant between the phenyl rings of the adjacent tubes (Fig. 1c, left). The building unit, inorganic tube and packing diagram of compound $\boldsymbol{S - 1}$ are also shown in Fig. 1a-c (right) for comparison.

Thermal analyses show that compounds $\mathbf{1}$ and $\mathbf{2}$ experience the first-step weight losses in the range $100-170{ }^{\circ} \mathrm{C}$ for $\mathbf{1}(10.9 \%$ for $\boldsymbol{R}-\mathbf{1}$, $11.6 \%$ for $S-1)$ and $120-200{ }^{\circ} \mathrm{C}$ for $2(11.4 \%$ for $\boldsymbol{R}-2$ and $S-2)$, respectively, corresponding to the removal of two coordinated water molecules (calcd $\mathbf{1 1 . 7 \%}$ for $\mathbf{1}$ and 2) (Fig. S7, ESI†). This is followed by a distinct plateau before a second weight loss step occurs above ca. $280{ }^{\circ} \mathrm{C}$, attributed to the combustion of the organic constituents and the collapse of the structure. The dehydration process is accompanied by a color change from purple red to blue for $\mathbf{1}$, and green to yellow for $\mathbf{2}$. The XRD measurements on $\boldsymbol{R}$-1-de and $\boldsymbol{R}$-2-de, obtained by thermal treatment at $180{ }^{\circ} \mathrm{C}$ (for $\boldsymbol{R}-\mathbf{1}$ ) or $200{ }^{\circ} \mathrm{C}$ (for $\boldsymbol{R}$-2) for two hours, reveal that the nanotubular structures are maintained after removing the coordination water. For $\boldsymbol{R} \mathbf{- 1}$, the immersion of the dehydrated samples in water leads to the recovery of the original phases (Fig. S10, ESI $\dagger$ ). While for $\boldsymbol{R}$-2, the dehydration/rehydration process is not reversible at room temperature (Fig. S11, ESI $\dagger$ ).

Solid-state circular dichroism (CD) spectra were obtained for enantio-isomers of $\mathbf{1}$ and 2. As shown in Fig. 2a, negative Cotton effects of $\boldsymbol{R - 1}$ are evident at $258 \mathrm{~nm}$ and positive dichroic signals are centered at 471, 489 and $556 \mathrm{~nm}$, while $\boldsymbol{S}$ - 1 exhibits the opposite sign of Cotton effects at the same wavelength. Compounds $\boldsymbol{R}-\mathbf{2}$ and $S$-2 exhibit mirror dichroic signals at $c a .261,418$ and $670 \mathrm{~nm}$ (Fig. 2b). These results further prove the enantiomeric nature of these compounds, with the optical activities originating from both the chiral phosphonate ligands and the metal centers. The chiral nature remains after dehydration, as confirmed by the presence of CD signals at $c a .262 \mathrm{~nm}$. Interestingly, the peaks in the visible region disappear in all four cases, indicating that the chirality in the metal centers is not retained after dehydration. The rehydration of
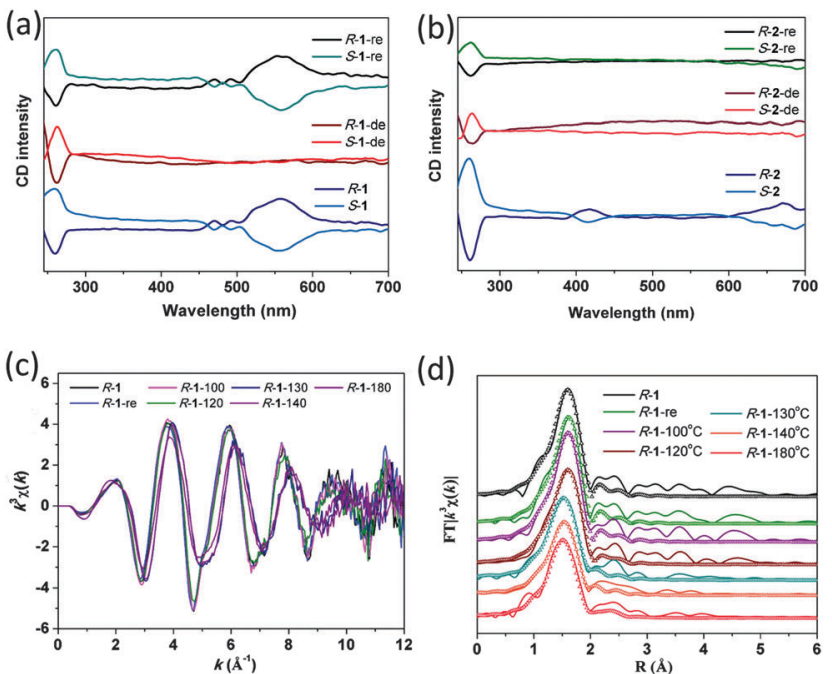

Fig. 2 Solid-state circular dichroism spectra for (a) compounds $\boldsymbol{R}-\mathbf{1}$ and $S-1$, and (b) $R-\mathbf{2}$ and $S-2$ before and after dehydration and rehydration. (c) Co-K edge $k^{3}$-weight EXAFS signals taken at RT for compound $\boldsymbol{R}-\mathbf{1}$ at different dehydration temperatures. (d) Fourier transformed space ( $R$ space) and their fitting curves (dotted lines) for $\boldsymbol{R}-\mathbf{1}$ at Co K-edge. 
$\boldsymbol{R}$-1-de and $\boldsymbol{S}$-1-de leads to the recovery of the CD signals in the UV-vis region. In contrast, the immersion of samples $\boldsymbol{R}$-2-de and $\boldsymbol{S}$-2-de in water does not change their CD spectra. The results demonstrate again that the dehydration/rehydration process is reversible for compounds $\boldsymbol{R}-\mathbf{1}$ and $\boldsymbol{S}-\mathbf{1}$, while not for compounds $\boldsymbol{R}-\mathbf{2}$ and $\boldsymbol{S}$-2. Furthermore, the second harmonic generation (SHG) measurements were carried out for the four compounds before and after dehydration. All exhibit SHG responses about 0.4 or 0.3 times that of urea.

To monitor the change in the local coordination sphere of the metal ions after dehydration, $\mathrm{Co}(\mathrm{Ni}) \mathrm{K}$-edge EXAFS spectroscopic measurements ${ }^{20}$ were conducted for $\boldsymbol{R}-\mathbf{1}$ and $\boldsymbol{R}-\mathbf{2}$ as well as their dehydrated samples pretreated at different temperatures for $1 \mathrm{~h}$ (Fig. S13 and S14, ESI $\dagger$ ). Curve-fitting was performed for the first FT peak in the $R$-space using Hanning windows (for $\boldsymbol{R}-1$ ) or KaiserBessel windows (for $\boldsymbol{R}$-2) by taking into account the $\mathrm{Co}-\mathrm{O}(\mathrm{N})$ or $\mathrm{Ni}-\mathrm{O}(\mathrm{N})$ coordination pairs (Fig. 2c and d and Fig. S15, S16, ESI $\dagger$ ). The extracted structural parameters are summarized in Tables S5 and $\mathrm{S} 6(\mathrm{ESI} \dagger)$. For $\boldsymbol{R} \mathbf{- 1}$, the data fit leads to five oxygen atoms at $2.07 \AA$ and one nitrogen atom at $2.25 \AA$, which are close to those obtained by the single crystal structural determination (av. 2.117 and $2.236 \AA$, respectively). Upon heating, both the $\mathrm{Co}-\mathrm{O}(\mathrm{N})$ bond lengths and the coordination number of cobalt remain almost the same up to $120{ }^{\circ} \mathrm{C}$. Significant structural change is observed when the sample is thermally treated at $130{ }^{\circ} \mathrm{C}$, where the $\mathrm{Co}^{\mathrm{II}}$ becomes fourcoordinated and the $\mathrm{Co}-\mathrm{O}(\mathrm{N})$ distances are shortened (Co-O: 1.98, Co-N: $2.14 \AA$ ). The coordination environment of cobalt in the fully dehydrated sample $\boldsymbol{R}-\mathbf{1 - 1 8 0}{ }^{\circ} \mathrm{C}$ is similar to that in $\boldsymbol{R - 1 - 1 3 0}{ }^{\circ} \mathrm{C}$. Rehydration of the sample $\boldsymbol{R}-\mathbf{1}-180{ }^{\circ} \mathrm{C}$ by immersing in water leads to the recovery of $\boldsymbol{R}-\mathbf{1}$, evidenced by the $\mathrm{Co}-\mathrm{O}(\mathrm{N})$ distances and coordination number of six (Table S5, ESI $\dagger$ ).

For $\boldsymbol{R}-2$, the data fit leads to five oxygen atoms at $2.05 \AA$ and one nitrogen atom at $2.15 \AA$, which are close to those obtained by the single crystal structure determination (av. 2.066 and $2.166 \AA$ ). In the fully dehydrated sample $\boldsymbol{R}-2-200{ }^{\circ} \mathrm{C}$, the coordination number of nickel is still six, and the $\mathrm{Ni}-\mathrm{O}(\mathrm{N})$ distances remain almost the same (Table S6, ESI $\dagger$ ). The result suggests that the vacant sites of the nickel ion after dehydration could be refilled with the neighboring phosphonate oxygen atoms, which may explain the irreversible dehydration/rehydration process for $\boldsymbol{R}-\mathbf{2}$ at room temperature. The EXAFS results are in agreement with the TG and XRD data.

Water adsorption and desorption isotherms were collected at $25{ }^{\circ} \mathrm{C}$ on the dehydrated samples of $\boldsymbol{R}-\mathbf{1}$ and $\boldsymbol{R}-\mathbf{2}$, pre-treated at $100{ }^{\circ} \mathrm{C}$ under vacuum for 12 hours. As shown in Fig. 3 and Fig. S17 (ESI $\dagger$ ), both experience a one-step adsorption process. The amount of water adsorbed at $P / P_{0}=0.98$ is 2.94 (for $\boldsymbol{R}$-1-de) and 2.79 (for $\boldsymbol{R}$-2-de) molecules of water per formula unit. Interestingly, the desorption isotherms display significant hysteresis in both cases and show a gradual release of water molecules upon decreasing the relative pressure. The number of water molecules per formula unit at $P / P_{0}=0.02$ is 1.98 for the cobalt sample and 1.31 for the nickel sample. The former agrees well with the two coordinated water molecules in compound $\boldsymbol{R}-\mathbf{1}$, indicating that each cobalt ion re-binds two water molecules which cannot be removed at $25^{\circ} \mathrm{C}$. The latter is much less than two coordination water molecules expected for $\boldsymbol{R}-\mathbf{2}$, again suggesting that the water molecules do not re-coordinate to

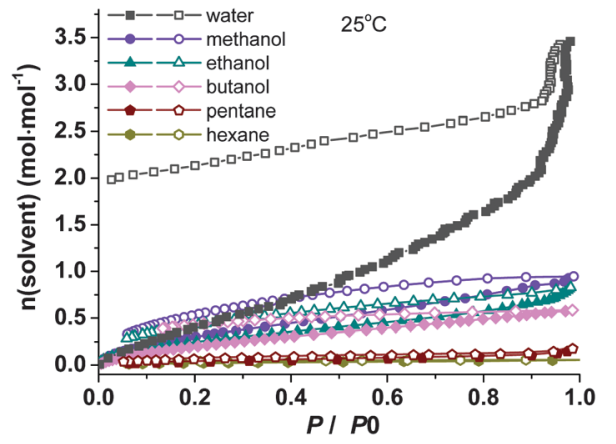

Fig. 3 The solvent adsorption (filled points) and desorption (open points) isotherms for compound $\boldsymbol{R}-\mathbf{1}$ at $25^{\circ} \mathrm{C}$.

the nickel ions after dehydration. We have repeated the water adsorption and desorption isotherms of both $\boldsymbol{R}-\mathbf{1}$ and $\boldsymbol{R}-\mathbf{2}$ three times without significant change in the curves.

The adsorption behavior of organic molecules such as alcohols and alkanes was also examined for the dehydrated samples of $\boldsymbol{R}-\mathbf{1}$ and $\boldsymbol{R}$-2. Fig. 3 shows the adsorption and desorption isotherms of $\boldsymbol{R}$-1-de at $25{ }^{\circ} \mathrm{C}$. The amounts adsorbed at $P / P_{0}=0.98$ are 1.15 molecules of methanol, 0.96 molecules of ethanol and 0.84 molecules of butanol per formula unit, which are significantly less compared with that of water $\left(2.94 \mathrm{~mol} \mathrm{~mol}^{-1}\right)$. In addition, the adsorption towards pentane and hexane is nearly zero. Similar behavior is observed for sample $\boldsymbol{R}$-2-de (Fig. S17, ESI $\dagger$ ). Noting that the kinetic diameters of water $(2.7 \AA)$ is smaller than those of methanol (3.6 $\AA$ ), ethanol (4.5 $\AA$ ), butanol (5.0 $)$ ) and the alkane molecules (4.3-4.5 $\mathrm{A}),{ }^{21}$ the highly selective water adsorption capabilities of $\boldsymbol{R}$-1-de and $\boldsymbol{R}$-2-de over alcohols and alkanes are attributed to the small diameter $(7.86 \AA)$ and also to the hydrophilic nature inside the nanotubes.

The $\mathrm{N}_{2}$ and $\mathrm{H}_{2}$ gas adsorption and desorption isotherms were also measured at $77 \mathrm{~K}$. The BET surface areas obtained from the $\mathrm{N}_{2}$ sorption isotherms are 10.2 and $12.0 \mathrm{~m}^{2} \mathrm{~g}^{-1}$ for $\boldsymbol{R}$-1-de and $\boldsymbol{R}$-2-de, respectively. As shown in Fig. S18 (ESI $\dagger$ ), compound $\boldsymbol{R}$-2-de can adsorb more $\mathrm{H}_{2}$ than $\boldsymbol{R}$-1-de at $77 \mathrm{~K}\left(10.4\right.$ vs. $3.56 \mathrm{~cm}^{3} \mathrm{~g}^{-1}$ at $100 \mathrm{kPa}$ ), the origin of which is not clear to us. Distinct hysteresis is observed in the $\mathrm{H}_{2}$ desorption isotherms in both cases. Apparently, the release of $\mathrm{H}_{2}$ molecules is very slow upon decreasing the pressure. The results are in agreement with the presence of nanotubes with small inner diameters.

In order to study the proton transportation capabilities of these nanotubular materials, we initially measured the proton conductivities of powder pellets of $\boldsymbol{R}-\mathbf{1}$ and $\boldsymbol{R}-\mathbf{2}$ by a quasi-four probe method using a Solartron SI 1260 impedance/gain-phase analyzer with a 1296 dielectric interface. The conductivities were determined from the semicircular Nyquist plots at different temperatures and relative humidities (RHs). It is found that the proton conductivities are $2.16 \times 10^{-6} \mathrm{~S} \mathrm{~cm}^{-1}$ for $\boldsymbol{R}-\mathbf{1}$ and $1.61 \times$ $10^{-6} \mathrm{~S} \mathrm{~cm}^{-1}$ for $\boldsymbol{R}-2$ at $25{ }^{\circ} \mathrm{C}$ and $95 \% \mathrm{RH}$. The values are highly humidity dependent, and drop to $1.21 \times 10^{-11}$ and $6.50 \times$ $10^{-12} \mathrm{~S} \mathrm{~cm}^{-1}$ for the two samples at $25{ }^{\circ} \mathrm{C}$ and $50 \% \mathrm{RH}$ (Fig. S21 and $\mathrm{S} 22, \mathrm{ESI} \dagger)$. The temperature dependence of the proton conductivities was measured in the range of $15-45{ }^{\circ} \mathrm{C}$ at $95 \% \mathrm{RH}$ for the two samples (Fig. S23-S26, ESI $\dagger$ ). The activation energies $\left(E_{\mathrm{a}}\right)$ are 
estimated to be 0.30 and $0.24 \mathrm{eV}$ (2nd cycle) for $\boldsymbol{R}-\mathbf{1}$ and $\boldsymbol{R}-\mathbf{2}$, respectively, suggesting a Grotthuss-type conduction mechanism. ${ }^{22}$

Noting that compounds $\boldsymbol{R}-\mathbf{1}$ and $\boldsymbol{R}-\mathbf{2}$ are neutral, both the proton source and carrier are likely coordinated water, where the acidity is enhanced by coordination to the metal ions. ${ }^{23}$ However, the conductivities of $\boldsymbol{R}-\mathbf{1}$ and $\boldsymbol{R}-\mathbf{2}$ are much lower compared with the other phosphonate-based MOFs. ${ }^{24}$ To check whether the conductivity originates from the proton transportation inside the nanotube, we performed the measurements using a single crystal of $\boldsymbol{R}-\mathbf{1}$ with dimensions $1.3 \times 0.1 \times 0.07 \mathrm{~mm}^{3}$. It is found that the conductivity along the tube direction is ca. $6.7 \times 10^{-11} \mathrm{~S} \mathrm{~cm}^{-1}$ at $25{ }^{\circ} \mathrm{C}$ and 95\% RH (Fig. S29, ESI $\dagger$ ). Obviously, the overall proton conductivity of the powder samples mainly arises from the boundary effects. The result is in agreement with the structures of $\boldsymbol{R}-\mathbf{1}$ and $\boldsymbol{R}-\mathbf{2}$, where the hydrogen-bonded six-member rings constructed by three $\mathrm{O} 2 \mathrm{~W}$ and three $\mathrm{O} 1$ atoms are not connected to neighboring rings through hydrogen bonds (Fig. 1d), thus blocking an efficient proton conducting pathway within the hydrophilic channels.

In summary, we have succeeded in obtaining the first examples of homochiral nanotubular metal phosphonates, namely, $(R)$ - or $(S)-\left[\mathrm{M}(\right.$ pemp $\left.)\left(\mathrm{H}_{2} \mathrm{O}\right)_{2}\right]\left(\mathrm{M}=\mathrm{Co}^{\mathrm{II}}, \mathrm{Ni}^{\mathrm{II}}\right)$. The fully dehydrated samples exhibit highly selective water adsorption capabilities over the alcohol and alkane molecules. Further work is in progress to understand the formation mechanism of these nanotubes and to explore new tubular metal phosphonates with expanded inner sizes.

This work is supported by the National Basic Research Program of China (2013CB922102) and the NSF of China (No. 21371094, $11135008,11305172)$. We thank the State Key Laboratory of Structure Chemistry, Fujian Institute of Research on the Structure of Matter (China), for the single crystal structural determination. We also thank Prof. Hui Zhang in Xiamen University for valuable suggestions in the CD measurements.

\section{Notes and references}

$\S$ Crystal data for $\boldsymbol{R}-1$ : hexagonal, $P 6_{3}, a=18.314(1) \AA ̊ \AA, c=6.168(1) \AA$, $V=1791.9(2) \AA^{3}, Z=6, F(000)=954, \rho_{\text {calcd }}=1.713 \mathrm{~g} \mathrm{~cm}^{-3}, \mu\left(\mathrm{Mo}_{\mathrm{K} \alpha}\right)=$ $1.579 \mathrm{~mm}^{-1}(\lambda=0.71073 \AA), R_{1}=0.045, \mathrm{w} R_{2}=0.141$, GooF $=1.03$, Flack parameter $=0.03(3)$. For $S$-1: hexagonal, $P 6_{3}, a=18.288(8) \AA$, $c=6.168(4) \AA, V=1786.5(1) \AA^{3}, Z=6, F(000)=954, \rho_{\text {calcd }}=1.718 \mathrm{~g} \mathrm{~cm}^{-3}$, $\mu\left(\mathrm{Mo}_{\mathrm{K} \alpha}\right)=1.584 \mathrm{~mm}^{-1}(\lambda=0.71073 \AA), R_{1}=0.052, \mathrm{w} R_{2}=0.123, \mathrm{GooF}=$ 1.05, Flack parameter $=0.06(3)$. $R$-2: hexagonal, $P 6_{3}, a=18.162(1) \AA$, $c=6.168(7) \AA, V=1762(2) \AA^{3}, Z=6, F(000)=954, \rho_{\text {calcd }}=1.741 \mathrm{~g} \mathrm{~cm}^{-3}$,

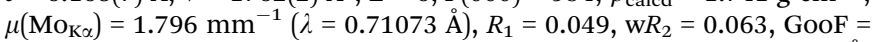
0.94 , Flack parameter $=0.05(4)$. For $S$-2: hexagonal, $P 6_{3}, a=18.081(2) \AA$, $c=6.1296(6) \AA, V=1735.5(3) \AA^{3}, Z=6, F(000)=960, \rho_{\text {calcd }}=1.768 \mathrm{~g} \mathrm{~cm}^{-3}$, $\mu\left(\mathrm{Mo}_{\mathrm{K} \alpha}\right)=1.824 \mathrm{~mm}^{-1}(\lambda=0.71073 \AA), R_{1}=0.031, \mathrm{w} R_{2}=0.082, \mathrm{GooF}=$ 1.09, Flack parameter $=0.02(2)$. CCDC $696828(\boldsymbol{R}-1), 696829(\boldsymbol{S}-1)$, $1060995(\boldsymbol{R}-2)$ and $696830(\boldsymbol{S}-2)$.

1 S. Iijima, Nature, 1991, 354, 56-58.

2 (a) W. Xiong, F. Du, Y. Liu, A. Perez Jr., M. Supp, T. S. Ramakrishnan, L. Dai and L. Jiang, J. Am. Chem. Soc., 2010, 132, 15839-15841; (b) V. Biju, Chem. Soc. Rev., 2014, 43, 744-764; (c) H. G. Park and Y. Jung, Chem. Soc. Rev., 2014, 43, 565-576.

3 (a) H. X. Sui, B. G. Han, J. K. Lee, P. Walian and B. K. Jap, Nature, 2001, 414, 872-878; (b) D. Fu, A. Libson, L. J. Miercke, C. Weitzman, P. Nollert, J. Krucinski and R. M. Stroud, Science, 2000, 290, 481-486. 4 C. N. R. Rao, S. R. C. Vivekchand, K. Biswas and A. Govindaraj, Dalton Trans., 2007, 3728-3749.
5 (a) D. T. Bong, T. D. Clark, J. R. Granja and M. R. Ghadiri, Angew. Chem., Int. Ed., 2001, 40, 988-1011; (b) V. G. Organo and D. M. Rudkevich, Chem. Commun., 2007, 3891-3899.

6 P. Thanasekaran, T.-T. Luo, C.-H. Lee and K.-L. Lu, J. Mater. Chem., 2011, 21, 13140-13149 and references therein.

7 G. Wu, J. Bai, Y. Jiang, G. Li, J. Huang, Y. Li, C. E. Anson, A. K. Powell and S. Qiu, J. Am. Chem. Soc., 2013, 135, 18276-18279.

8 K. Otsubo, Y. Wakabayashi, J. Ohara, S. Yamamoto, H. Matsuzaki, H. Okamoto, K. Nitta, T. Uruga and H. Kitagawa, Nat. Mater., 2011, 10, 291-295.

9 (a) T. Panda, T. Kunduz and R. Banerjee, Chem. Commun., 2012, 48, 5464-5466; (b) D. K. Unruh, K. Gojdas, A. Libo and T. Z. Forbes, J. Am. Chem. Soc., 2013, 135, 7398-7401; (c) P. Neuhaus, A. Cnossen, J. Q. Gong, L. M. Herz and H. L. Anderson, Angew. Chem., Int. Ed., 2015, 54, 7344-7348.

10 (a) G. W. Orr, L. J. Barbour and J. L. Atwood, Science, 1999, 285, 1049-1052; (b) H.-T. Zhang, Y.-Z. Li, T.-W. Wang, E. N. Nfor, H.-Q. Wang and X.-Z. You, Eur. J. Inorg. Chem., 2006, 3532-3536.

11 (a) H. K. Ngo and W. B. Lin, Top. Catal., 2005, 34, 85-92; (b) Y. Liu, W. M. Xuan and Y. Cui, Adv. Mater., 2010, 22, 4112-4135; (c) P. Peluso, V. Mamane and S. Cossu, J. Chromatogr. A, 2014, 1363, 11-26; (d) J. Crassous, Chem. Soc. Rev., 2009, 38, 830; (e) C. Train, M. Gruselle and M. Verdaguer, Chem. Soc. Rev., 2011, 40, 3297.

12 (a) M. E. Davis, Chem. Mater., 2014, 26, 239-245; (b) A. Rojas and M. A. Camblor, Angew. Chem., Int. Ed., 2012, 51, 3854-3856.

13 (a) S.-T. Wu, Z.-W. Cai, Q.-Y. Ye, C.-H. Weng, X.-H. Huang, X.-L. Hu, C.-C. Huang and N.-F. Zhuang, Angew. Chem., Int. Ed., 2014, 53, 12860-12864; (b) X. Zhao, M. Wong, C. Mao, T. X. Trieu, J. Zhang, P. Feng and X. Bu, J. Am. Chem. Soc., 2014, 136, 12572-12575.

14 (a) A. Clearfield, Prog. Inorg. Chem., 1998, 47, 371-510; (b) A. Clearfield and K. D. Demadis, Metal Phosphonate Chemistry: From Synthesis to Applications, The Royal Society of Chemistry, 2012.

15 (a) G. K. H. Shimizu, R. Vaidhyanathan and J. M. Taylor, Chem. Soc. Rev., 2009, 38, 1430-1449; (b) K. J. Gagnon, H. P. Perry and A. Clearfield, Chem. Rev., 2012, 112, 1034-1054; (c) M. T. Wharmby, J. P. S. Mowat, S. P. Thompson and P. A. Wright, J. Am. Chem. Soc., 2011, 133, 1266-1269; (d) T. Zheng, J. M. Clemente-Juan, J. Ma, L. Dong, S.-S. Bao, J. Huang, E. Coronado and L.-M. Zheng, Chem. - Eur. J., 2013, 19, 16394-16402.

16 (a) D. M. Poojary, D. Grohol and A. Clearfield, Angew. Chem., Int. Ed. Engl., 1995, 34, 1508-1510; (b) D. M. Poojary, A. Cabeza, M. A. G. Aranda, S. Bruque and A. Clearfield, Inorg. Chem., 1996, 35, 1468-1473.

17 (a) H. L. Ngo and W. B. Lin, J. Am. Chem. Soc., 2002, 124, 14298-14299; (b) Q. Yue, J. Yang, G. H. Li, G. D. Li and J. S. Chen, Inorg. Chem., 2006, 45, 4431-4439; (c) X. Shi, G. Zhu, S. Qiu, K. Huang, J. Yu and R. Xu, Angew. Chem., Int. Ed., 2004, 43, 6482-6485.

18 (a) X.-G. Liu, S.-S. Bao, Y.-Z. Li and L.-M. Zheng, Inorg. Chem., 2008, 47, 5525-5527; (b) X.-G. Liu, K. Zhou, J. Dong, C.-J. Zhu, S.-S. Bao and L.-M. Zheng, Inorg. Chem., 2009, 48, 1901-1905; (c) X.-G. Liu, J. Huang, S.-S. Bao, Y.-Z. Li and L.-M. Zheng, Dalton Trans., 2009, 9837-9842; (d) T.-T. Wang, S.-S. Bao, J. Huang, Y.-Z. Li and L.-M. Zheng, Dalton Trans., 2013, 42, 1842-1847; (e) Z.-S. Cai, S.-S. Bao, M. Ren and L.-M. Zheng, Chem. - Eur. J., 2014, 20, 17137-17142.

19 G. B. Hix, B. M. Kariuki, S. Kitchin and M. Tremayne, Inorg. Chem., 2001, 40, 1477-1481.

20 D. C. Koningsberger and R. Prins, X-ray Absorption: Principle, Applications, Techniques of EXAFS, SEXAFS and XANES, Wiley, New York, 1988.

21 H. Wu, Q. Gong, D. H. Olson and J. Li, Chem. Rev., 2012, 112, 836-868.

22 N. Agmon, Chem. Phys. Lett., 1995, 244, 456-462.

23 N. C. Jeong, B. Samanta, C. Y. Lee, O. K. Farha and J. T. Hupp, J. Am. Chem. Soc., 2012, 134, 51-54.

24 (a) P. Ramaswamy, N. Wong and G. K. H. Shimizu, Chem. Soc. Rev., 2014, 43, 5913-5932 and references therein; (b) M. Bazaga-García, R. M. P. Colodrero, M. Papadaki, P. Garczarek, J. Zoń, P. OliveraPastor, E. R. Losilla, L. León-Reina, M. A. G. Aranda, D. ChoquesilloLazarte, K. D. Demadis and A. Cabeza, J. Am. Chem. Soc., 2014, 136, 5731-5739; (c) S.-S. Bao, K. Otsubo, J. M. Taylor, Z. Jiang, L.-M. Zheng and H. Kitagawa, J. Am. Chem. Soc., 2014, 136, 9292-9295; (d) P. Ramaswamy, N. E. Wong, B. S. Gelfand and G. K. H. Shimizu, J. Am. Chem. Soc., 2015, 137, 7640-7643. 